\title{
Relationship of Catheter Contact Angle and Contact Force with Contact Area on the Surface of Heart Muscle Tissue in Cardiac Catheter Ablation
}

\author{
Kriengsak Masnok $^{1}$ and Nobuo Watanabe (i] ${ }^{1,2}$ \\ ${ }^{1}$ Functional Control Systems, Graduate School of Engineering and Science, Shibaura Institute of Technology, Saitama, Japan; \\ and ${ }^{2}$ Department of Bio-Science and Engineering, College of Systems Engineering and Science, Shibaura Institute of \\ Technology, Saitama, Japan
}

(Received 20 October 2020; accepted 16 February 2021; published online 15 March 2021)

Associate Editor Karen May-Newman oversaw the review of this article

\begin{abstract}
Purpose-The aims of this study were to develop an experimental procedure for setting the catheter angle with respect to the surface of the heart muscle and the catheter contact force and to investigate the catheter contact area on the heart muscle as a function of catheter contact angle and force.

Methods-Visualization tests were performed for 5 contact angles $\left(0^{\circ}, 30^{\circ}, 45^{\circ}, 60^{\circ}\right.$, and $\left.90^{\circ}\right)$ and 8 contact forces $(2,4,6$, $10,15,20,30$, and 40 gf). Each experiment was repeated 6 times with 2 different commercially available catheter tips. Results - The morphology of the contact area was classified into rectangular, circular, ellipsoidal, and semi-ellipsoidal. The correlation between contact force and contact area was a logarithmic function; increasing contact force was associated with increased contact area. At the same contact force, the correlation between contact angle and contact area was inverse; decreasing contact angle was associated with a corresponding increase in contact area.

Conclusion-Both the catheter contact angle and contact force substantially impact the contact area and morphology in catheter ablation procedures.
\end{abstract}

Keywords-Catheter ablation, Contact force, Contact angle, Contact area, Tachyarrhythmia.

\section{INTRODUCTION}

Over the past three decades, cardiac catheter ablation therapy has become a widely used and effective treatment for tachyarrhythmia. ${ }^{7,9,10,14,24,31}$ In this treatment, radiofrequency current is applied to the heart, heating the target area to a temperature exceeding $50{ }^{\circ} \mathrm{C}$ through resistive heating, ${ }^{19}$ thereby creating a lesion that isolates the abnormal electric pathway. ${ }^{8,17}$ Earlier studies have revealed several factors that correlate with lesion size, evaluated in terms of ablated area, volume, and depth. ${ }^{2,18,28,30}$ These factors include ablation circuit impedance, ${ }^{8,30}$ electrical power, ${ }^{16,21,25}$ energy delivery, ${ }^{11,13}$ catheter diameter, ${ }^{15,26}$ exposure time, ${ }^{8,16}$ contact force, $, 1,5,16,21,22,30$ ablation electrode temperature, ${ }^{12,29}$ irrigation saline flow amount, $, 525,28$ and blood flow near the myocardial surface. ${ }^{6,11,20,23}$ Among these factors, catheter contact force is reported to show a strongly positive correlation with lesion size. ${ }^{1,3-5,22,27}$

In addition to these factors, we hypothesized that the catheter contact angle with respect to the surface of the heart muscle would also have a substantial effect. During radiofrequency current catheter ablation, the catheter tip should contact the heart tissue surface at a variety of angles. However, no studies to date have investigated the relationship between the catheter tip and contact area with the heart muscle.

Against this backdrop, the purpose of this study was to develop an experimental procedure for setting the catheter angle with respect to the surface of the heart muscle and the catheter contact force, as well as to investigate the catheter contact area on the heart muscle as a function of catheter contact angle and contact force. 


\section{METHODS}

\section{Heart Muscle Surface Flattener and Different Open-Loop Irrigated Catheter Tips}

Most of the surface of the heart is round, and the state of catheter contact would vary according to clinical conditions. Therefore, to provide better reproducibility of our in vitro experiments, we developed a special instrument that precisely adjusts the catheter angle between the catheter tip and the heart muscle.

The instrument consists of a heart muscle surface flattener and catheter tip angle setter. As part of the heart muscle surface flattener, a circular crystalline acrylic plate with a thickness of $12 \mathrm{~mm}$ and a diameter of $130 \mathrm{~mm}$ was used to flatten the surface of porcine heart tissue and fix its position at a specific location and orientation, ensuring that all experiments using this plate will maintain uniformity.

The porcine heart was obtained from a slaughterhouse, cut into pieces, and stored in a refrigerator. Before the experiment, the pieces were removed from the refrigerator and kept at room temperature under moist conditions to prevent drying. The porcine heart tissue was sandwiched between the acrylic plate and a soft sponge placed in a stainless bowl. The surface of the heart muscle surface was flattened by adjusting the amount of the sponge. The catheter contact experiments were performed through a hole $(20 \mathrm{~mm} \times 50$ $\mathrm{mm})$ in the acrylic plate, as shown in Fig. 1a. All experiments were performed within 3 days after the pig was sacrificed at the slaughterhouse.
Two different open-loop irrigated catheter tips were used in this study (Fig. 1b). One was the IntellaNav $\mathrm{Mifi}^{\mathrm{TM}}$ OI (7 Fr/4.5 mm 7.5 Fr; PMR9620, Boston Scientific, Inc.; top of Fig. 1b), which is representative of flat-tip catheters. It was $110 \mathrm{~cm}$ long, with a tip length of $2.33 \mathrm{~mm}$, and had a standard curve style. The other catheter was an Abbott TactiCath ${ }^{\mathrm{TM}}$ (7 Fr/3.5 mm 7.5 Fr; Quadripolar, PN-004075, St. Jude Medical, Inc.; bottom of Fig. 1b), which is representative of round-tip catheters. It was $115 \mathrm{~cm}$ long, with a tip length of $2.33 \mathrm{~mm}$, and had a steerable curve style. Both catheters were open-loop irrigated catheters, with six small irrigation holes circumferentially located on the lateral surface of the tip. Irrigation of the catheter tip was designed to reduce excessive heating of the tissue and blood at the catheter tip. The main difference between the two catheters is the shape of the end tip.

\section{Experimental Procedure and Evaluation}

To elucidate the effects of the catheter contact angle and contact force on the contact area of the heart tissue surface, we developed a special experimental procedure that enables the setting of various catheter contact angles $\left(0^{\circ}, 30^{\circ}, 45^{\circ}, 60^{\circ}\right.$, and $\left.90^{\circ}\right)$ using a special acrylic tube guide, as well as the measurement of the contact force. In the experimental setup, a digital force sensor (FGP-0.5, Nidec-Shimpo Corporation) was mounted on a motion stage (FGS-5000TV, Nidec-Shimpo Corporation), the position of which can be controlled vertically. Using this setup, the catheter

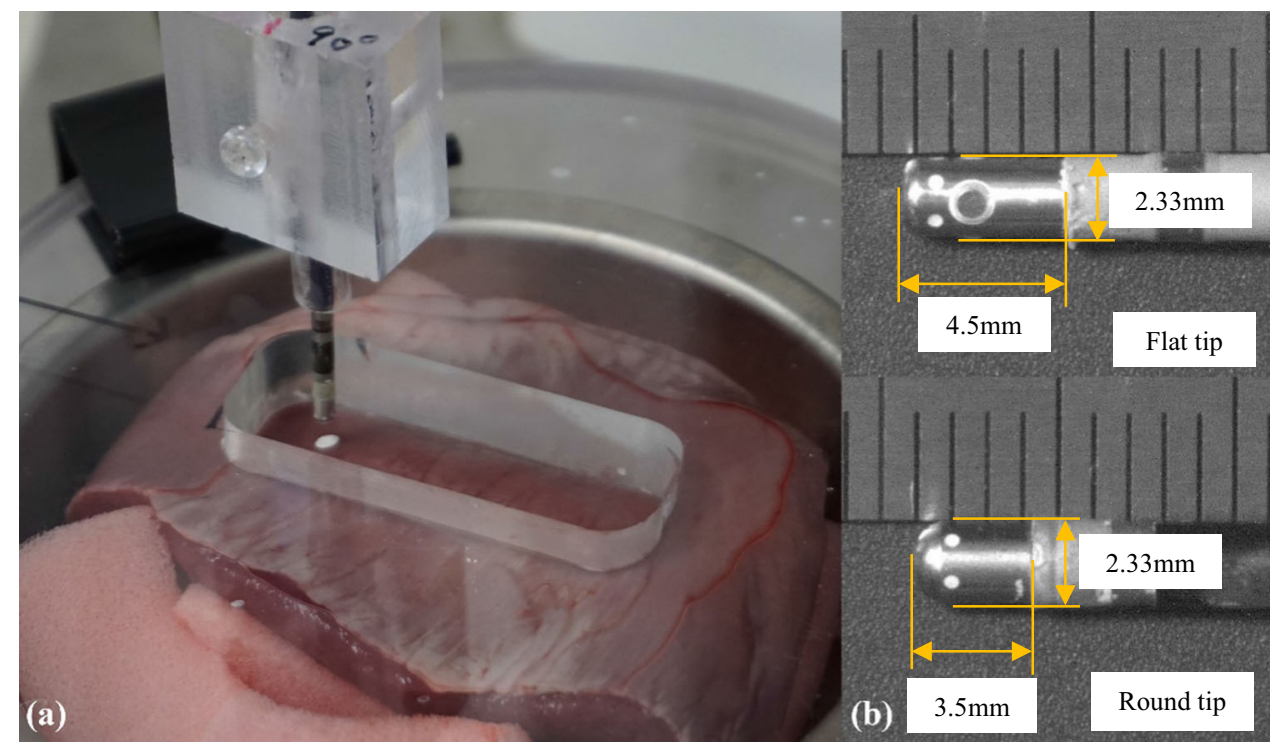

FIGURE 1. Heart muscle surface flattener and shape of the catheter tip; (a) photograph of the heart muscle surface flattener. The heart muscle tissue is sandwiched between a flat acrylic plate and a soft sponge, which are placed in a stainless bowl, and the surface of the heart muscle was flattened by adjusting the amount of the sponge in the bottom of the bowl. (b) Ablation catheter tips with two shapes were used: flat (top) and round (bottom). 
contact force and contact angle could be precisely controlled. The system was operated using commercial software (FGT-TV) running on a computer, as shown in Fig. 2.

White soluble ink (Pen Cure, Japan Pen Company) was overlaid on the metal electrode of the catheter tip to visualize the contacted area on the heart tissue surface. Then, the 8 levels of contact force within the clinically used range $(2,4,6,10,15,20,30$, and 40 gf) were applied to the cardiac muscle in line with the typical clinical contact force ranges. ${ }^{3,4,27}$ Using this process, the catheter contact area-visualization test was repeated 6 times each for the 5 contact angles and 8 contact forces to ensure equal distribution of contact force. In the final step, all of the catheter contact areas for each condition were photographed for the evaluation of contact area through image analysis. In total, 480 experiments were performed.

\section{Morphological Evaluation of Catheter Contact Area}

Image analysis of photographs of the catheter contact area was performed to evaluate the morphology of the contact area. The image analysis program MATLAB (Version 2019a) was used to perform the following actions. First, the raw color image of the contact area was manually segmented into individual lesion images and converted into a grayscale image, and finally the grayscale image was binarized. Next, the catheter contact area on the heart tissue surface was calculated. To understand the morphology of the contact area, the centroid of each contact area image was aligned to create a reference point for comparison. Then, the image was rotated about the centroid to align each area's longest axis parallel to the vertical direction. The average morphology of the contact area was derived from six experimentally acquired images. The morphological characteristics corresponding to physical parameters were also evaluated. All statistical analyses were performed using GraphPad Prism software (Version 8.4.3).

\section{RESULTS}

\section{Contact Area Morphology}

Figure 3 shows the four distinct morphologies of the contact area with a contact angle of $0^{\circ}$ using the flat-tip catheter and contact angles of $0^{\circ}, 30^{\circ}$, and $90^{\circ}$ using the round-tip catheter. These images show that the contact angle and shape of the catheter tip can affect the contact area morphology. For example, the morphology differs according to the shape of the catheter tip, even when both are applied at a contact force of 2 gf and a contact angle at $0^{\circ}$. In contrast, the morphology was similar when both shapes were applied at a contact force of $2 \mathrm{gf}$ and a contact angle at 90 . Further details about the differences in contact area

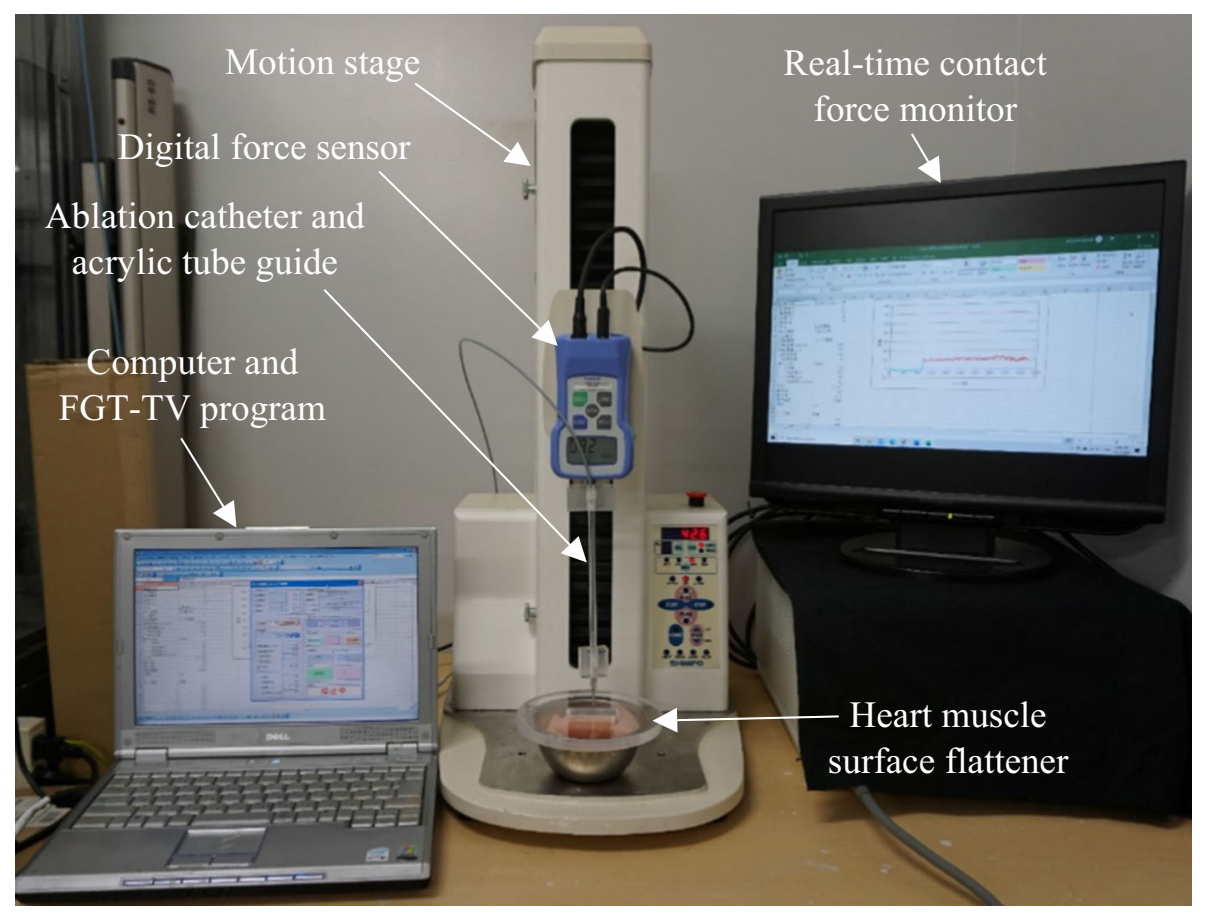

FIGURE 2. Experimental setup. A compact desktop test stand equipped with a digital force gauge was controlled using an FGTTV software link from a computer. In this picture, the acrylic tube guide for $90^{\circ}$ was used. 


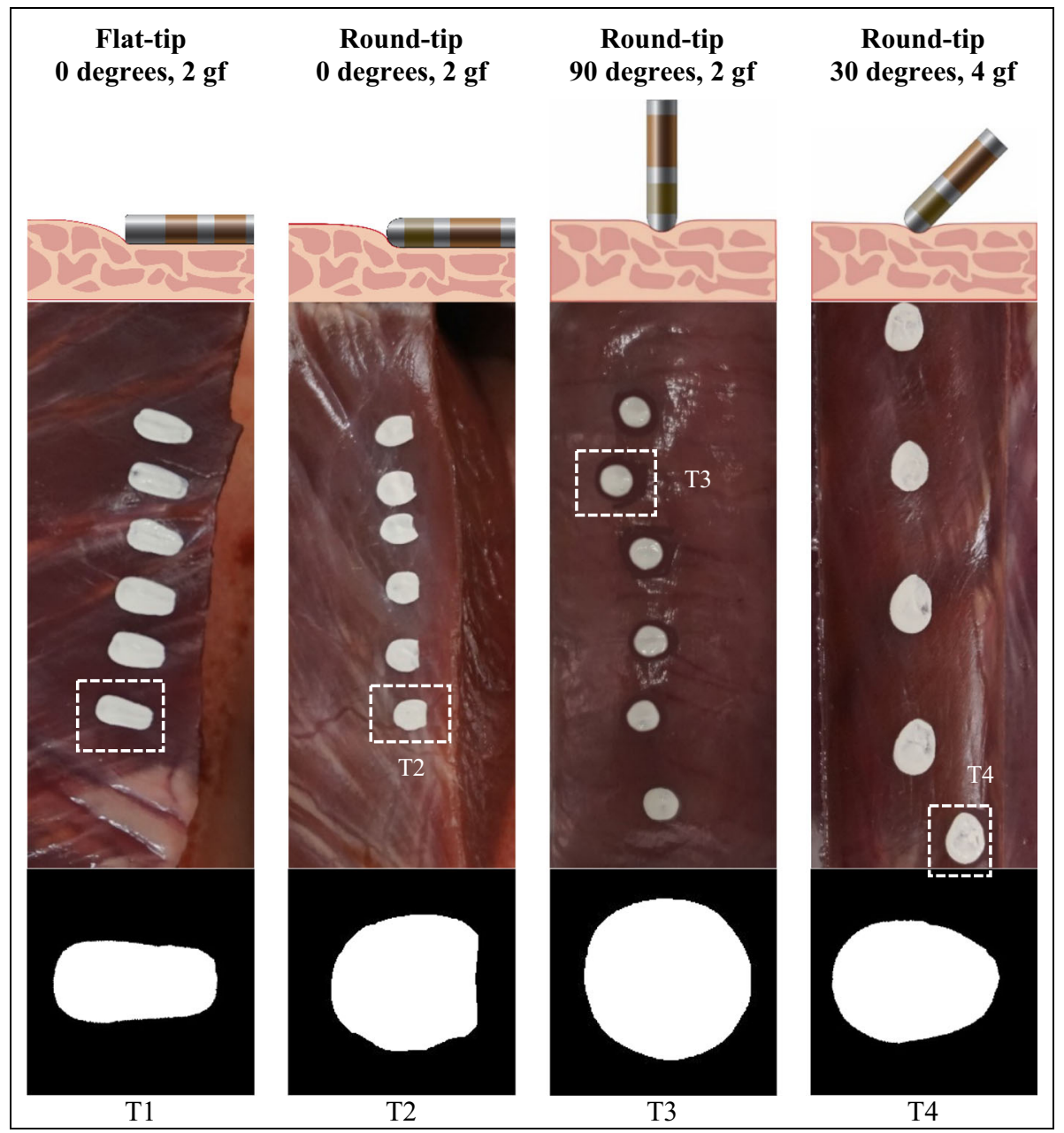

FIGURE 3. Morphology of the contact area on a porcine heart under various contact conditions. T1-T4 represent the morphology of the four types of contact area.

morphology will be discussed later in the "Discussion" section.

\section{Average Contact Area}

Figure 4 shows the image analysis flow process for evaluating the morphology of the contact area and the average contact area on a porcine heart with a contact angle of $90^{\circ}$ and a contact force of $30 \mathrm{gf}$ using the round-tip catheter.

Data of average contact areas, standard deviations, and percentage of contact area for flat-tip and roundtip catheters are shown in Tables 1 and 2, respectively. The ratio of the area of the catheter in contact with heart muscle to the catheter tip surface area was calculated by the following equation:

$\begin{aligned} \text { Percentagecontactarea }= & \left(\frac{\text { Catheter } / \text { heartcontactarea }}{\text { Cathetertipsurfacearea }}\right) \\ & \times 100,\end{aligned}$ where the catheter tip surface area of the flat-tip catheter is $37.26 \mathrm{~mm}^{2}$ and that of the round-tip catheter is $25.67 \mathrm{~mm}^{2}$.

The standard SI unit for force is the Newton $(\mathrm{N})$, but gram-force (gf) is frequently used to measure contact force in the field of catheter ablation research $(1 \mathrm{gf}=0.00981 \mathrm{~N}$, which is the force acting on a mass of $1 \mathrm{~g}$ under the Earth's gravitational acceleration of $9.81 \mathrm{~m} / \mathrm{s}^{2}$ ). The contact forces tested in this study were $2,4,6,10,15,20,30$, and $40 \mathrm{gf}$, which correspond to $0.0196,0.0392,0.0588,0.098,0.147,0.196,0.294$, and $0.392 \mathrm{~N}$, respectively.

Figure 5 shows a plot of the catheter contact areas created with the contact forces on the $x$-axis and the contact area on the $y$-axis for both catheter shapes. This plot illustrates the correlation between contact force, contact angle, and contact area. The results revealed a positive correlation between contact force and contact area, in which increased contact force was associated with increased contact area. Moreover, the 

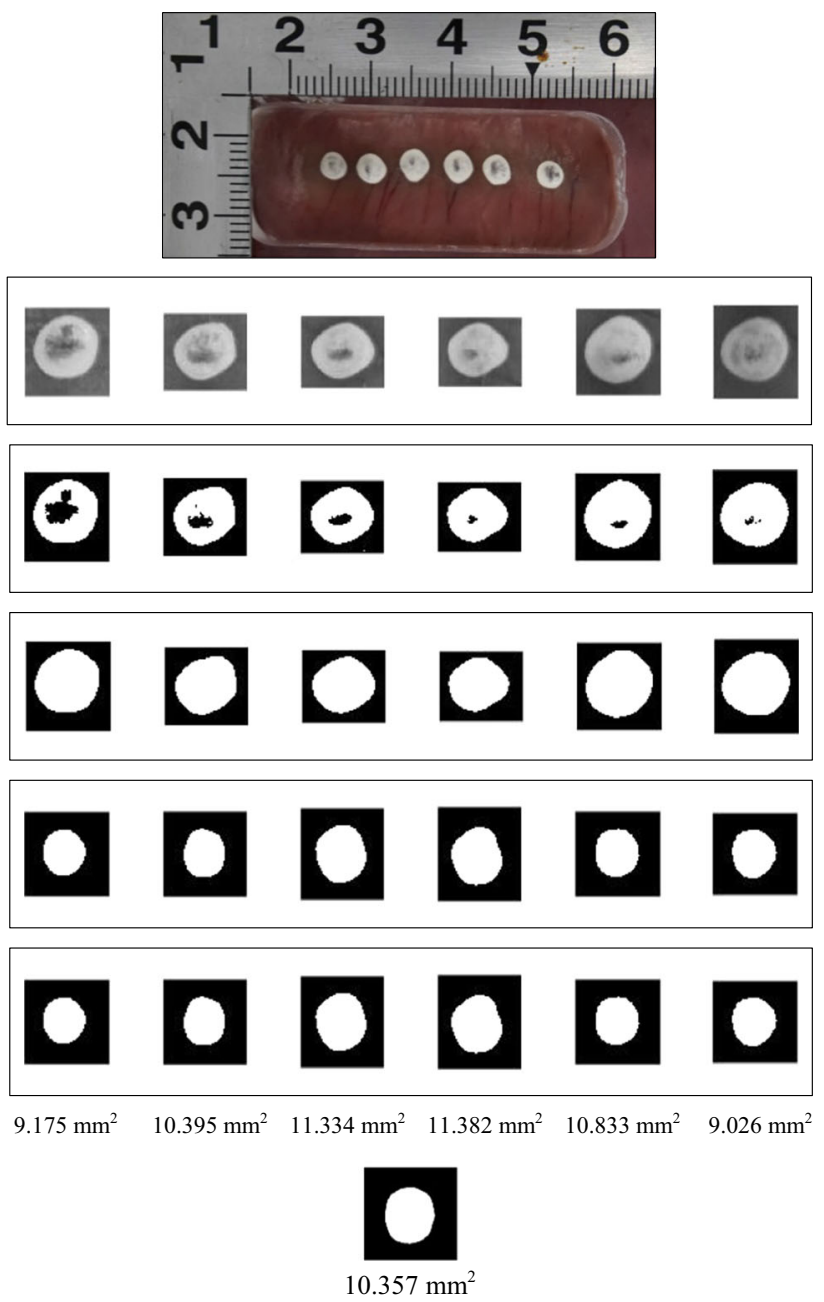

Imported raw image

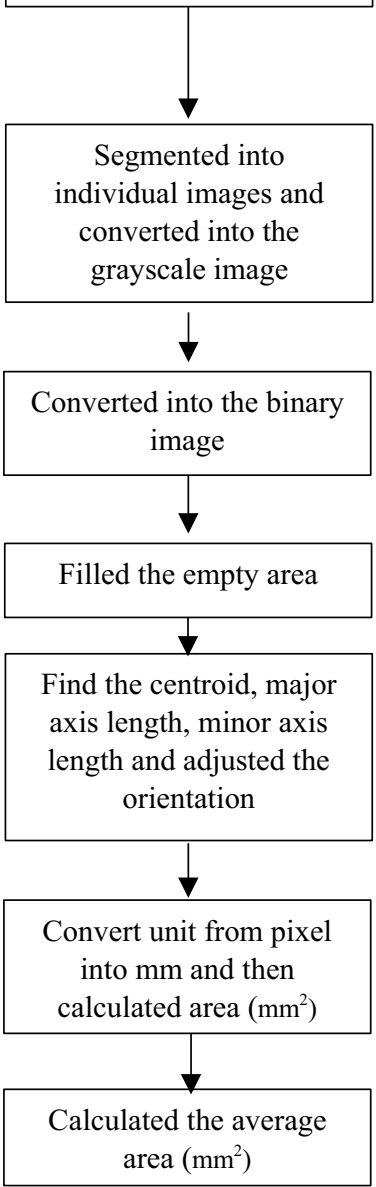

FIGURE 4. Chart of the flow process for evaluating the morphology of the contact area and the average contact area at a contact angle of $90^{\circ}$ and a contact force of $30 \mathrm{gf}$ using a round-tip catheter.

contact angle had as strong an effect on the contact area as the contact force did. At the same contact force, the correlation between contact angle and contact area was inverse; that is, a smaller contact angle was associated with an increased contact area. The logarithmic approximation formulas for expressing the relationship between contact force and contact area for each catheter contact angle are shown in Table 3. The data reveal that the correlation between contact force and the contact area is a logarithmic function with $\mathrm{R}$ squared $\left(R^{2}\right)$ being nearly equal to 1 .

Figure 6 shows binarized images of the average contact areas under the various conditions ( 8 contact forces and 5 contact angles) when using the flat-tip and round-tip catheters. These data clearly show that the contact angle had as much influence as the contact force on the contact area. For example, using the flattip catheter at a contact angle of $90^{\circ}$, the contact force increased from 2 to $4,6,10,15,20,30$, and $40 \mathrm{gf}$, and the average contact area increased from 3.445 to 4.392 , $5.627,6.879,8.363,7.405,9.508$, and $12.589 \mathrm{~mm}^{2}$, respectively. In addition, using the round-tip catheter at a contact angle of $90^{\circ}$, the contact force increased from 2 to $4,6,10,15,20,30$, and $40 \mathrm{gf}$, and the average contact area increased from 3.829 to $6.309,7.797$, $7.990,8.535,9.340,10.357$, and $11.914 \mathrm{~mm}^{2}$, respectively. Similar trends were seen for both shapes of catheters at contact angles of $60^{\circ}, 45^{\circ}, 30^{\circ}$, and $0^{\circ}$.

\section{DISCUSSION}

\section{Major Findings}

Our major findings are as follows: (i) the morphology of the contact area can be divided into four types: rectangular, circular, ellipsoidal, and semi-ellipsoidal. The morphology of the contact area indicates that (ii) the correlation between contact force and contact area 
TABLE 1. Average contact area and percentage contact area when using the flat-tip catheter $\left(\mathrm{mm}^{2}\right)$.

\begin{tabular}{|c|c|c|c|c|c|c|c|c|c|c|c|c|}
\hline \multirow[b]{3}{*}{ Contact angle } & \multicolumn{12}{|c|}{ Contact force (gf) } \\
\hline & \multicolumn{3}{|c|}{2} & \multicolumn{3}{|c|}{4} & \multicolumn{3}{|c|}{6} & \multicolumn{3}{|c|}{10} \\
\hline & AVG CA & SD & PCA (\%) & AVG CA & SD & PCA (\%) & AVG CA & SD & PCA (\%) & AVG CA & SD & PCA (\%) \\
\hline $0^{\circ}$ & 11.424 & 1.123 & 31 & 10.861 & 1.188 & 29 & 10.547 & 1.079 & 28 & 14.041 & 1.245 & 38 \\
\hline $30^{\circ}$ & 6.002 & 0.908 & 16 & 7.406 & 0.594 & 20 & 7.941 & 1.625 & 21 & 9.607 & 1.284 & 26 \\
\hline $45^{\circ}$ & 7.058 & 0.928 & 19 & 7.027 & 0.608 & 19 & 10.199 & 0.873 & 27 & 10.463 & 0.883 & 28 \\
\hline $60^{\circ}$ & 4.641 & 0.605 & 12 & 7.247 & 1.228 & 19 & 8.163 & 1.791 & 22 & 10.094 & 1.996 & 27 \\
\hline \multirow[t]{3}{*}{$90^{\circ}$} & 3.445 & 0.831 & 9 & 4.392 & 0.514 & 12 & 5.627 & 0.555 & 15 & 6.879 & 0.874 & 18 \\
\hline & \multicolumn{12}{|c|}{ Contact force (gf) } \\
\hline & \multicolumn{3}{|c|}{15} & \multicolumn{3}{|c|}{20} & \multicolumn{3}{|c|}{30} & \multicolumn{3}{|c|}{40} \\
\hline Contact angle & AVG CA & SD & PCA (\%) & AVG CA & SD & PCA (\%) & AVG CA & SD & PCA (\%) & AVG CA & SD & PCA (\%) \\
\hline $0^{\circ}$ & 15.458 & 1.392 & 41 & 15.358 & 1.624 & 41 & 16.405 & 1.050 & 44 & 19.097 & 1.294 & 51 \\
\hline $30^{\circ}$ & 13.178 & 2.103 & 35 & 14.644 & 2.609 & 39 & 11.769 & 1.914 & 32 & 14.759 & 1.196 & 40 \\
\hline $45^{\circ}$ & 11.820 & 0.680 & 32 & 12.842 & 1.438 & 34 & 14.860 & 1.672 & 40 & 19.533 & 1.361 & 52 \\
\hline $60^{\circ}$ & 11.131 & 1.590 & 30 & 11.431 & 1.699 & 31 & 12.114 & 1.443 & 33 & 13.515 & 0.895 & 36 \\
\hline $90^{\circ}$ & 8.363 & 0.982 & 22 & 7.405 & 1.126 & 20 & 9.508 & 1.040 & 26 & 12.589 & 0.812 & 34 \\
\hline
\end{tabular}

AVG CA average contact area, $S D$ standard deviation, $P C A$ percentage contact area.

TABLE 2. Average contact area and percentage contact area when using the round-tip catheter $\left(\mathrm{mm}^{2}\right)$.

\begin{tabular}{|c|c|c|c|c|c|c|c|c|c|c|c|c|}
\hline \multirow[b]{3}{*}{ Contact angle } & \multicolumn{12}{|c|}{ Contact force (gf) } \\
\hline & \multicolumn{3}{|c|}{2} & \multicolumn{3}{|c|}{4} & \multicolumn{3}{|c|}{6} & \multicolumn{3}{|c|}{10} \\
\hline & AVG CA & SD & PCA (\%) & AVG CA & SD & PCA (\%) & AVG CA & SD & PCA (\%) & AVG CA & SD & PCA (\%) \\
\hline $0^{\circ}$ & 6.365 & 0.508 & 25 & 8.730 & 0.840 & 34 & 9.039 & 1.040 & 35 & 10.325 & 1.159 & 40 \\
\hline $30^{\circ}$ & 6.055 & 1.075 & 24 & 6.999 & 0.825 & 27 & 9.982 & 0.768 & 39 & 12.579 & 1.107 & 49 \\
\hline $45^{\circ}$ & 3.592 & 0.493 & 14 & 4.906 & 0.421 & 19 & 5.547 & 0.629 & 22 & 6.815 & 0.898 & 27 \\
\hline $60^{\circ}$ & 3.699 & 0.724 & 14 & 5.869 & 0.719 & 23 & 6.782 & 0.821 & 26 & 8.222 & 0.625 & 32 \\
\hline \multirow[t]{3}{*}{$90^{\circ}$} & 3.829 & 0.294 & 15 & 6.309 & 0.320 & 25 & 7.797 & 1.134 & 30 & 7.990 & 0.553 & 31 \\
\hline & \multicolumn{12}{|c|}{ Contact force (gf) } \\
\hline & \multicolumn{3}{|c|}{15} & \multicolumn{3}{|c|}{20} & \multicolumn{3}{|c|}{30} & \multicolumn{3}{|c|}{40} \\
\hline Contact angle & AVG CA & SD & PCA (\%) & AVG CA & SD & PCA (\%) & AVG CA & SD & PCA (\%) & AVG CA & SD & PCA (\%) \\
\hline $0^{\circ}$ & 11.779 & 1.292 & 46 & 12.343 & 1.042 & 48 & 13.661 & 0.852 & 53 & 15.578 & 1.274 & 61 \\
\hline $30^{\circ}$ & 14.417 & 2.141 & 56 & 13.697 & 1.857 & 53 & 17.693 & 1.394 & 65 & 16.788 & 0.581 & 65 \\
\hline $45^{\circ}$ & 8.123 & 0.652 & 32 & 9.704 & 0.841 & 38 & 12.730 & 1.583 & 50 & 13.725 & 1.954 & 53 \\
\hline $60^{\circ}$ & 9.354 & 0.811 & 36 & 10.275 & 0.868 & 40 & 10.464 & 1.740 & 41 & 14.310 & 2.286 & 56 \\
\hline $90^{\circ}$ & 8.535 & 0.751 & 33 & 9.340 & 0.638 & 36 & 10.357 & 1.039 & 40 & 11.914 & 0.909 & 46 \\
\hline
\end{tabular}

AVG CA average contact area, $S D$ standard deviation, $P C A$ percentage contact area.

is a logarithmic function; that is, increased contact force was associated with increased contact area, and the contact angle has as strong an effect on the contact area as contact force does. (iii) There is an inverse correlation between contact angle and contact area; smaller contact angle is associated with increased contact area.

\section{Morphological Characterization of the Contact Area}

To elucidate the effects of catheter contact angle and contact force on the contact area, we constructed a heart muscle surface flattener to maintain a flat surface to test a range of contact angles. This instrument was designed to achieve improved experimental reproducibility. Although in routine clinical ablation pro- 
(a)

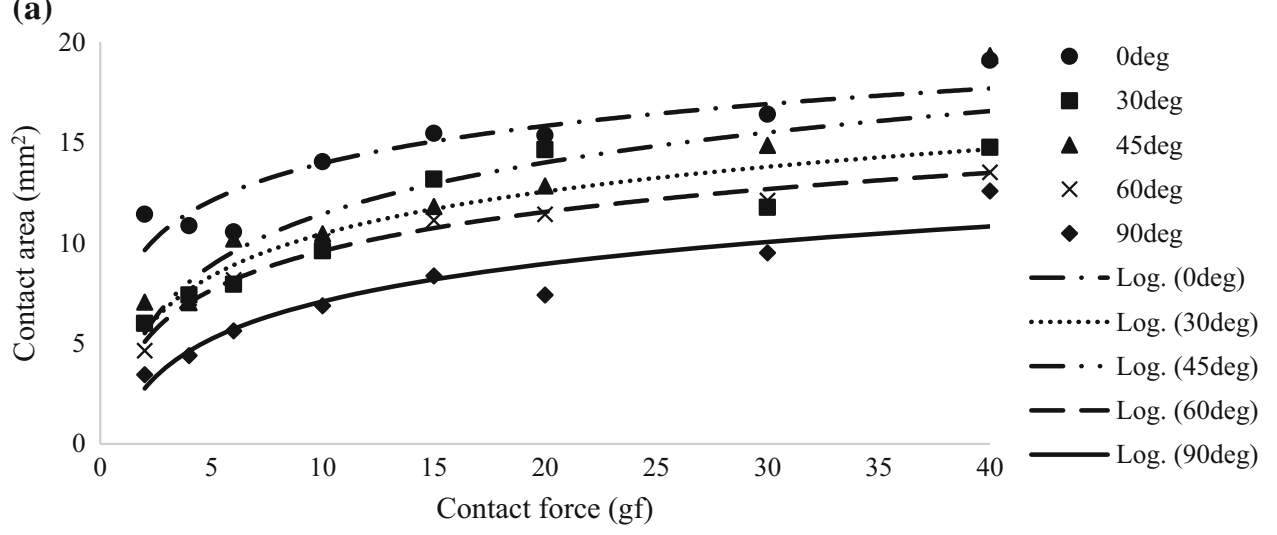

(b)

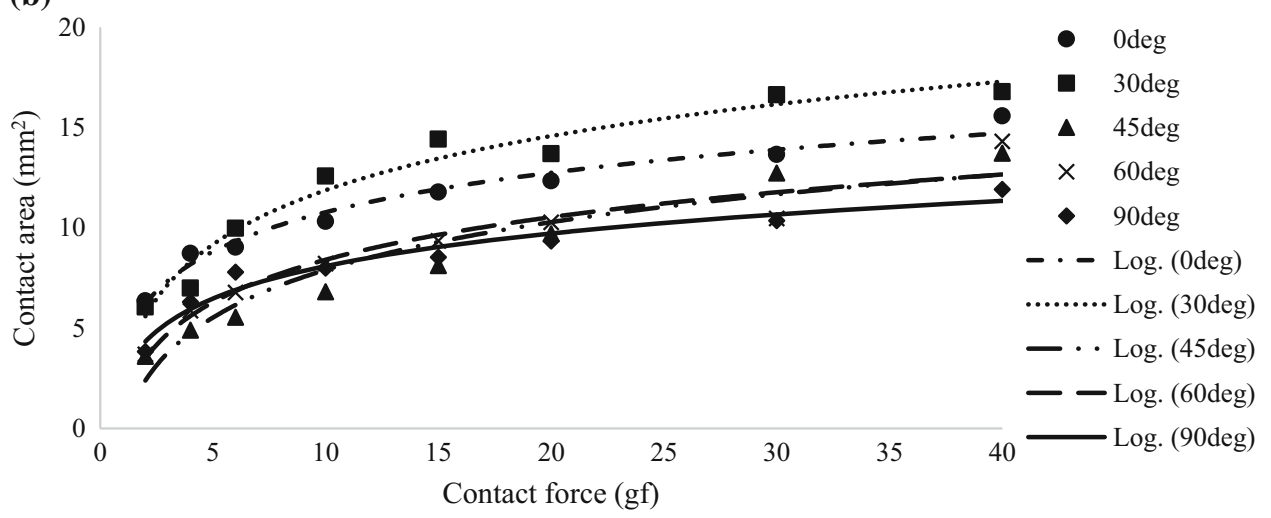

FIGURE 5. Plot of average contact area and contact force for (a) flat-tip catheters and (b) round-tip catheters at each contact angle.

TABLE 3. Approximation formulas expressing the relationship between catheter contact force and contact area for each catheter contact angle, where $x$ is catheter contact force ( $\mathrm{gf}), y$ is catheter contact area $\left(\mathrm{mm}^{2}\right)$, and $R^{2}$ is coefficient of determination, respectively.

\begin{tabular}{lllll}
\hline & \multicolumn{1}{c}{ Flat-tip } & & \multicolumn{2}{c}{ Round-tip } \\
\cline { 2 - 3 } Angle $\left(^{\circ}\right)$ & Approximation formula & $R^{2}$ & & Approximation formula \\
\hline 0 & $y=2.685 \ln (x)+7.782$ & 0.837 & $y=2.837 \ln (x)+4.251$ & $R^{2}$ \\
30 & $y=3.036 \ln (x)+3.465$ & 0.845 & $y=3.903 \ln (x)+2.890$ & 0.974 \\
45 & $y=3.689 \ln (x)+2.952$ & 0.867 & $y=3.429 \ln (x)+0.012$ & 0.926 \\
60 & $y=2.807 \ln (x)+3.137$ & 0.984 & $y=3.062 \ln (x)+1.363$ & 0.936 \\
90 & $y=2.693 \ln (x)+0.892$ & 0.893 & $y=2.341 \ln (x)+2.709$ & 0.953 \\
\hline
\end{tabular}

cedures, the surface of the heart tissue is not flat, our data clearly demonstrated that the contact angle and shape of the catheter tip substantially affected the contact area morphology. In summary, we categorized the morphology of the contact area into four types, as shown in Fig. 7. A notable difference occurred when the catheter angle became parallel to the heart surface. Contact area morphology became rectangular when using a flat end tip and semi-ellipsoidal when using a round end tip. This observation clearly shows the effect of the shape of the catheter. When contact is made at a perpendicular angle, the contact area morphology is circular because the projected area of both catheters is a circle, and thus the contact area becomes circular. When the catheter is inclined, the contact area becomes ellipsoidal like an egg. Those morphological character trends changed similarly for both round- and flat-tip catheters except in the parallel $\left(0^{\circ}\right)$ direction.

\section{Correlation Between Contact Force and Contact Area}

Catheter contact force shows a strong positive correlation with contact area. When the contact force was increased, the contact area also increased. These results 
Contact angle (degrees)

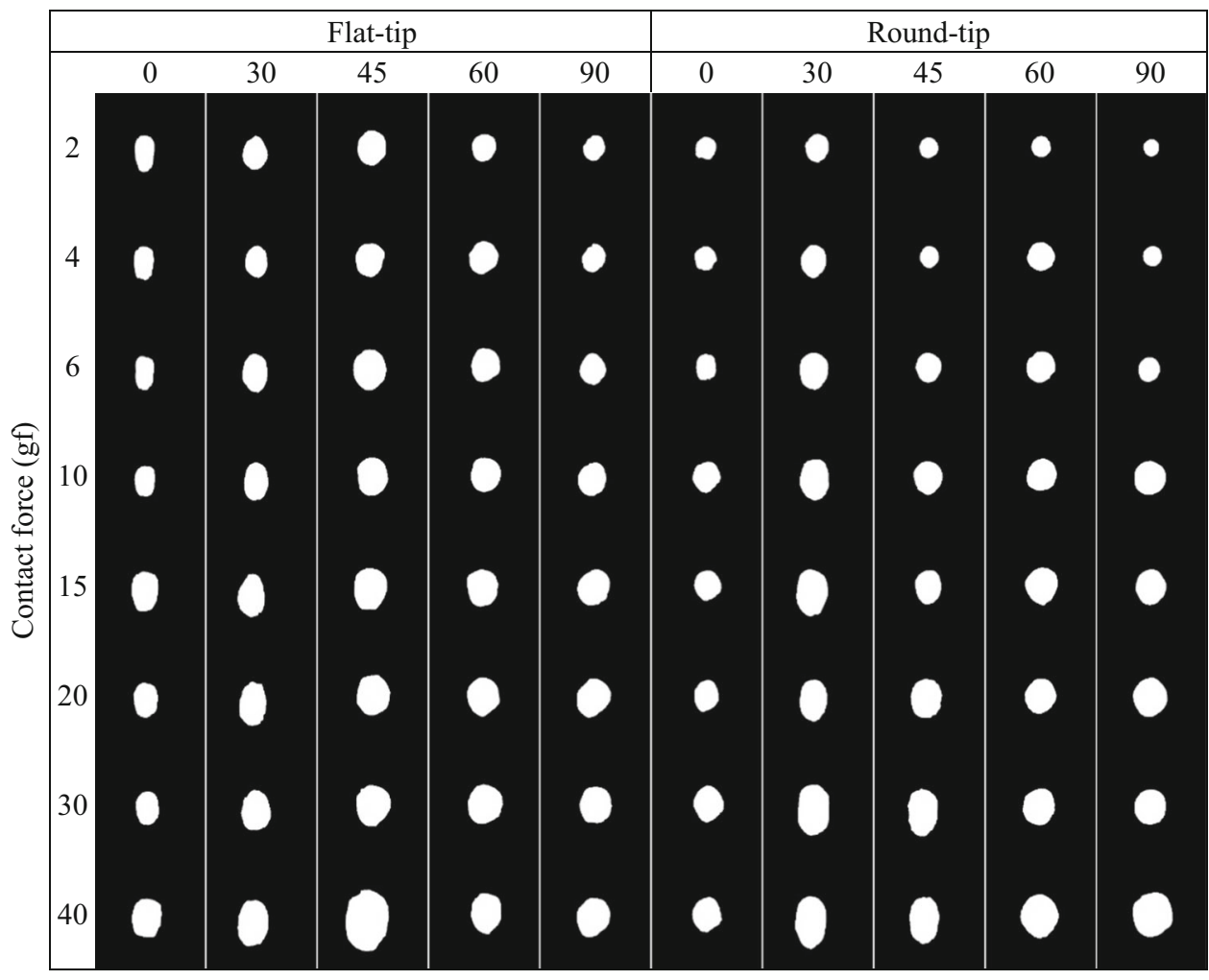

FIGURE 6. Average contact area morphology using flat-tip and round-tip catheters under various conditions.

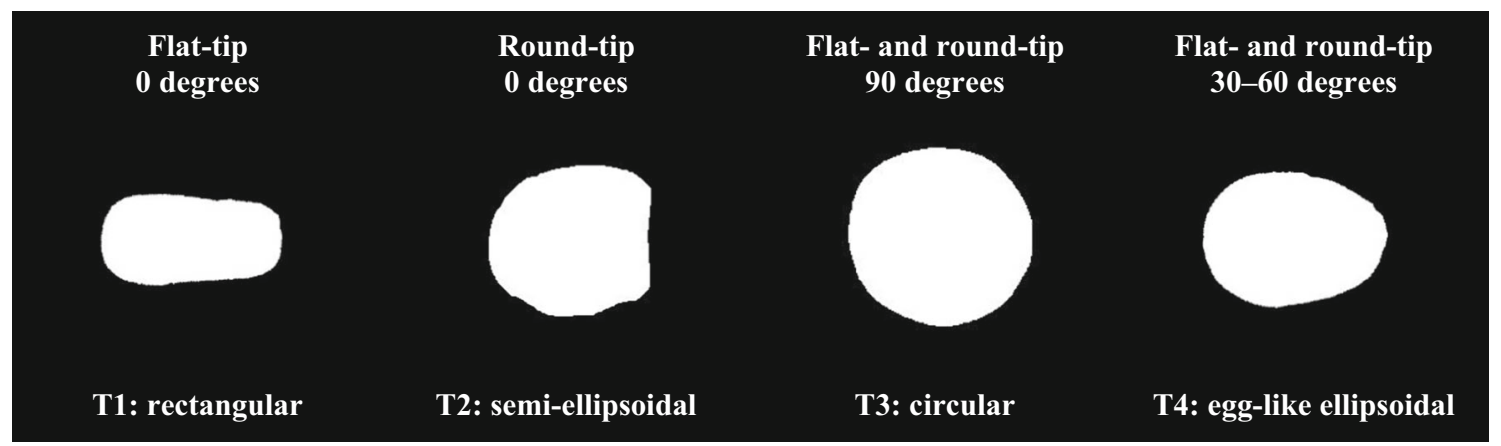

FIGURE 7. Contact area morphologies. The T1 morphology represents the contact area of the flat-tip catheter at a contact angle of $0^{\circ}$. The T2 morphology represents the contact area of the round-tip catheter at a contact angle of $0^{\circ}$. The T3 morphology represents the contact area of both the round- and flat-tip catheters at a contact angle of $90^{\circ}$. The T4 morphology represents the contact area of both the round- and flat-tip catheters at a contact angle of between $30^{\circ}$ and $60^{\circ}$.

are similar to those in earlier reports ${ }^{1,3-5,22,27}$; however, it is essential to consider the small changes in contact area that occurred at higher contact forces. The contact area increased monotonically but logarithmically. The slope of the graph changes slightly when the contact force is between 15 and 40 gf, which is in contrast to the greater change in slope when during initial contact when the contact force ranges from 2 to $15 \mathrm{gf}$. The equation for estimating contact area might help those performing this procedure to understand the relationships among the parameters and to calculate the contact area as a function of contact force at each contact angle. Our data suggest a limit to the extent by which lesion size can be increased by increasing the contact force. The catheter contact angle relative to the heart muscle tissue surface can also needs to be considered when calculating the desired lesion size. 


\section{Correlation Between Contact Angle and Contact Area}

The results clearly demonstrate that the contact angle is a key determinant of the contact area morphology. In addition, the contact angle substantially affects the contact area of the catheter tip regardless of the contact force. For the flat-tip catheter, the minimum contact area was produced at a contact angle of $90^{\circ}$ and increased with decreasing contact angle from $90^{\circ}$ to $60^{\circ}, 45^{\circ}, 30^{\circ}$, and $0^{\circ}$. For the round-tip catheter, the minimum contact area was produced at a contact angle of $90^{\circ}$ and increased with decreasing contact angle from $90^{\circ}$ to $60^{\circ}, 45^{\circ}, 0^{\circ}$, and $30^{\circ}$. For both catheter shapes, the contact area progressively increased when the contact angle was decreased. However, our results show a difference between the flat- and roundtip catheters at $0^{\circ}$ and $30^{\circ}$. These differences were due to the difference in shape and size between the two shapes of catheter tip. The two catheters used for this study were made by different manufacturers and differ in size according to their shape, especially at a contact angle between $0^{\circ}$ and $30^{\circ}$. The round-tip catheter makes less surface contact with the heart tissue surface compared with the flat-tip catheter. Despite this fact, the results of the experiment as a whole show a similar tendency.

\section{Clinical Implications}

Our data should be useful for those performing this procedure to understand the relation among the parameters and plan their treatment strategy beforehand. From our experiments, the contact area morphology was derived as a function between the contact angle and contact force. It is reasonable to assume that the contact area is directly related to the area of resulting lesion.

\section{Study Limitations}

This study has several limitations. First, we aimed to test our assumptions about contact angle, contact force, and contact area by using two different shapes of commercially available catheter tips. The two catheters were made by different manufacturers, and thus have some differences in design. Accordingly, we did not compare the differences in results between the catheters. Second, to provide better reproducibility of our in vitro experiments, we developed a special instrument that precisely adjusts the catheter angle between the catheter tip and the heart muscle. The instrument consists of a heart muscle surface flattener and a catheter-tip-angle setter. In clinical practice the shape of the heart tissue surface varies according to the part of the heart, and thus the catheter tip orientation can rarely be optimized due to restricting structures such as trabeculated muscle, valves, or the papillary muscle. Nevertheless, at the present stage of research on catheter ablation (pre-clinical experiment studies), it necessary to perform tests on flat surfaces to clearly demonstrate the specific effects of the catheter contact angle and contact force on the contact area of the heart tissue surface. Lastly, to produce effective ablation lesions, the depth of the lesion is at least as important as the ablation size. In this study, we did not investigate whether the catheter contact angle and contact force affected the depth of the ablation lesion; however, we conducted experiments to elucidate the effect of the catheter contact angle and contact force on the contact area. Our findings might be validated in the near future through numerical simulations such as the Finite Elemental Method, which can be used to estimate cardio-muscular deformation in response to catheter tip contact or a practical investigation through an in vitro heart muscle ablation experiment.

\section{CONCLUSION}

This study clearly demonstrated a substantial impact of the contact angle and contact force of a catheter on the size and morphology of the contact area in catheter ablation procedures. The contact area should be directly related to the lesion area. Our data may help doctors understand the relationships among contact angle, contact force, and contact area in ablation therapy procedures. Such information should help doctors plan appropriate treatment strategies in consideration of each patient's conditions.

\section{ACKNOWLEDGMENTS}

The authors thank Abbott Medical Japan and Boston Scientific Japan for their kind provision of catheters.

\section{AUTHOR CONTRIBUTIONS}

Both authors contributed to the study conception and design. Material preparation, data collection, and analysis were performed by KM and NW. The first draft of the manuscript was written by KM and both authors commented on subsequent drafts of the manuscript. All authors read and approved the final manuscript. 


\section{FUNDING}

This research was supported by the Research and Development Supporting Fund from the Shibaura Institute of Technology, and a Scholarship from the Ministry of Education, Culture, Sports, Science and Technology of Japan.

\section{DATA AVAILABILITY}

The datasets generated during and/or analyzed during the current study are available from the corresponding author upon reasonable request.

\section{CODE AVAILABILITY}

MATLAB (Version 2019a) and GraphPad Prism software (Version 8.4.3) were used in this study. Code generated and/or analyzed during the current study are available from the corresponding author upon reasonable request.

\section{CONFLICT OF INTEREST}

Both authors received consulting/advisory support from Abbott Medical Japan and Boston Scientific Japan. The authors declare that they have no conflicts of interest.

\section{ETHICAL APPROVAL}

Not applicable.

\section{INFORMED CONSENT}

No human studies were carried out by the authors for this article.

\section{OPEN ACCESS}

This article is licensed under a Creative Commons Attribution 4.0 International License, which permits use, sharing, adaptation, distribution and reproduction in any medium or format, as long as you give appropriate credit to the original author(s) and the source, provide a link to the Creative Commons licence, and indicate if changes were made. The images or other third party material in this article are included in the article's Creative Commons licence, unless indicated otherwise in a credit line to the material. If material is not included in the article's Creative Commons licence and your intended use is not permitted by statutory regulation or exceeds the permitted use, you will need to obtain permission directly from the copyright holder. To view a copy of this licence, visit http://crea tivecommons.org/licenses/by/4.0/.

\section{REFERENCES}

${ }^{1}$ Ariyarathna, N., S. Kumar, S. P. Thomas, W. G. Stevenson, and G. F. Michaud. Role of contact force sensing in catheter ablation of cardiac arrhythmias: evolution or history repeating itself? JACC Clin Electrophysiol 4(6):707723, 2018. https://doi.org/10.1016/j.jacep.2018.03.014.

${ }^{2}$ Avitall, B., K. Mughal, J. Hare, R. Helms, and D. Krum. The effects of electrode-tissue contact on radiofrequency lesion generation. Pacing Clin Electrophysiol 20(12):28992910, 1997. https://doi.org/10.1111/j.1540-8159.1997.tb054 58.x.

${ }^{3}$ Borregaard, R., H. K. Jensen, B. J. Tofig, S. A. Thrysøe, C. Gerdes, J. C. Nielsen, et al. Is the knowledge of contact force beneficial in pulmonary vein antrum isolation? Scand Cardiovasc J 51(3):129-137, 2017. https://doi.org/10.1080/ 14017431.2017.1285043.

${ }^{4}$ Conti, S., R. Weerasooriya, P. Novak, J. Champagne, H. E. Lim, L. Macle, et al. Contact force sensing for ablation of persistent atrial fibrillation: a randomized, multicenter trial. Heart Rhythm 15(2):201-208, 2018. https://doi.org/ 10.1016/j.hrthm.2017.10.010.

${ }^{5}$ Franco, E., D. Rodríguez Muñoz, R. Matía, A. Hernández-Madrid, I. Sánchez Pérez, J. L. Zamorano, et al. Contact force-sensing catheters: performance in an ex vivo porcine heart model. $J$ Interv Card Electrophysiol 53(2):141-150, 2018. https://doi.org/10.1007/s10840-018-0 435-y.

${ }^{6}$ Fuller, I. A., and M. A. Wood. Intramural coronary vasculature prevents transmural radiofrequency lesion formation: implications for linear ablation. Circulation 107(13):1797-1803, 2003. https://doi.org/10.1161/01.CIR. 0000058705.97823.F4.

${ }^{7}$ Grubb, C. S., M. Lewis, W. Whang, A. Biviano, K. Hickey, M. Rosenbaum, et al. Catheter ablation for atrial tachycardia in adults with congenital heart disease: electrophysiological predictors of acute procedural success and post-procedure atrial tachycardia recurrence. JACC Clin Electrophysiol 5(4):438-447, 2019. https://doi.org/10.1016/ j.jacep.2018.10.011.

${ }^{8}$ Haines, D. Biophysics of ablation: application to technology. J Cardiovasc Electrophysiol 15(s10):S2-S11, 2004. h ttps://doi.org/10.1046/j.1540-8167.2004.15102.x.

${ }^{9}$ Hosseini, S. M., G. Rozen, A. Saleh, J. Vaid, Y. Biton, K. Moazzami, et al. Catheter ablation for cardiac arrhythmias: utilization and in-hospital complications, 2000 to 2013. JACC Clin Electrophysiol 3(11):1240-1248, 2017. h ttps://doi.org/10.1016/j.jacep.2017.05.005.

${ }^{10}$ Ichijo, S., S. Miyazaki, S. Kusa, H. Nakamura, H. Hachiya, T. Kajiyama, et al. Impact of catheter ablation of atrial fibrillation on long-term clinical outcomes in patients with heart failure. J Cardiol 72(3):240-246, 2018. https://d oi.org/10.1016/j.jjcc.2018.02.012.

${ }^{11}$ Iso, K., Y. Okumura, I. Watanabe, K. Nagashima, K. Sonoda, R. Kogawa, et al. Wall thickness of the pulmonary vein-left atrial junction rather than electrical information as 
the major determinant of dormant conduction after contact force-guided pulmonary vein isolation. $J$ Interv Card Electrophysiol 46(3):325-333, 2016. https://doi.org/10.1007/ s10840-016-0147-0.

${ }^{12}$ Iwasawa, J., J. S. Koruth, J. Petru, L. Dujka, S. Kralovec, K. Mzourkova, et al. Temperature-controlled radiofrequency ablation for pulmonary vein isolation in patients with atrial fibrillation. $J$ Am Coll Cardiol 70(5):542-553, 2017. https://doi.org/10.1016/j.jacc.2017.06.008.

${ }^{13}$ Kalman, J. M., A. P. Fitzpatrick, J. E. Olgin, M. C. Chin, R. J. Lee, M. M. Scheinman, et al. Biophysical characteristics of radiofrequency lesion formation in vivo: dynamics of catheter tip-tissue contact evaluated by intracardiac echocardiography. Am Heart J 133(1):8-18, 1997. https://d oi.org/10.1016/s0002-8703(97)70242-4.

${ }^{14}$ Murakoshi, N., and K. Aonuma. Catheter ablation for ventricular tachyarrhythmia in patients with channelopathies. J Arrhythm 32(5):404-410, 2016. https://doi. org/10.1016/j.joa.2016.01.011.

${ }^{15}$ Müssigbrodt, A., M. Grothoff, B. Dinov, J. Kosiuk, S. Richter, P. Sommer, et al. Irrigated tip catheters for radiofrequency ablation in ventricular tachycardia. BioMed Res Int 2015:389294, 2015. https://doi.org/10.1155/2015/3 89294.

${ }^{16}$ Nakagawa, H., and W. M. Jackman. The role of contact force in atrial fibrillation ablation. $J$ Atr Fibrillation 7(1):1027, 2014. https://doi.org/10.4022/jafib.1027.

${ }^{17}$ Nath, S., C. Lynch, J. G. Whayne, and D. E. Haines. Cellular electrophysiological effects of hyperthermia on isolated guinea pig papillary muscle. Implications for catheter ablation. Circulation 88(4):1826-1831, 1993. https:// doi.org/10.1161/01.CIR.88.4.1826.

${ }^{18}$ Okumura, Y., S. B. Johnson, T. J. Bunch, B. D. Henz, C. J. O'Brien, and D. L. Packer. A systematical analysis of in vivo contact forces on virtual catheter tip/tissue surface contact during cardiac mapping and intervention. J Cardiovasc Electrophysiol 19(6):632-640, 2008. https://doi.org/ 10.1111/j.1540-8167.2008.01135.x.

${ }^{19}$ Page, R. L., J. A. Joglar, M. A. Caldwell, H. Calkins, J. B. Conti, B. J. Deal, et al. 2015 ACC/AHA/HRS Guideline for the Management of Adult Patients with Supraventricular Tachycardia: A Report of the American College of Cardiology/American Heart Association Task Force on Clinical Practice Guidelines and the Heart Rhythm Society. Circulation 133(14):e471-e505, 2016.

${ }^{20}$ Sacher, F., M. Wright, N. Derval, A. Denis, K. Ramoul, P. Pascale, et al. Endocardial versus epicardial ventricular radiofrequency ablation: utility of in vivo contact force assessment. Circ Arrhythm Electrophysiol 6(1):144-151, 2013. https://doi.org/10.1161/CIRCEP.11.

${ }^{21}$ Shah, D. C., H. Lambert, H. Nakagawa, A. Langenkamp, N. Aeby, and G. Leo. Area under the real-time contact force curve (force-time integral) predicts radiofrequency lesion size in an in vitro contractile model. $J$ Cardiovasc Electrophysiol 21(9):1038-1043, 2010. https://doi.org/10.11 $11 /$ j. 1540-8167.2010.01750.x.

${ }^{22}$ Shah, D. C., and M. Namdar. Real-time contact force measurement: a key parameter for controlling lesion creation with radiofrequency energy. Circ Arrhythm Electro- physiol 8(3):713-721, 2015. https://doi.org/10.1161/ CIRCEP.115.002779.

${ }^{23}$ Simmers, T. A., J. M. T. De Bakker, R. Coronel, F. H. M. Wittkampf, F. J. Van Capelle, M. J. Janse, et al. Effects of intracavitary blood flow and electrode-target distance on radiofrequency power required for transient conduction block in a Langendorff-perfused canine model. $J$ Am Coll Cardiol 31(1):231-235, 1998. https://doi.org/10.1016/S073 5-1097(97)00435-X.

${ }^{24}$ Sohns, C., J. H. Nürnberg, J. Hebe, W. Duckeck, R. Ventura, F. Konietschke, et al. Catheter ablation for atrial fibrillation in adults with congenital heart disease: lessons learned from more than 10 years following a sequential ablation approach. JACC Clin Electrophysiol. 5(4):733743, 2018. https://doi.org/10.1016/j.jacep.2018.01.015.

${ }^{25}$ Takami, M., H. I. Lehmann, K. D. Parker, K. M. Welker, S. B. Johnson, and D. L. Packer. Effect of left atrial ablation process and strategy on microemboli formation during irrigated radiofrequency catheter ablation in an in vivo model. Circ Arrhythm Electrophysiol 9(1):e003226, 2016. https://doi.org/10.1161/CIRCEP.115.003226.

${ }^{26}$ Tsai, C. F., C. T. Tai, W. C. Yu, Y. J. Chen, M. H. Hsieh, C. E. Chiang, et al. Is 8-mm more effective than 4-mm tip electrode catheter for ablation of typical atrial flutter? Circulation 100(7):768-771, 1999. https://doi.org/10.1161/ 01.CIR.100.7.768.

${ }^{27}$ Ullah, W., A. McLean, M. H. Tayebjee, D. Gupta, M. R. Ginks, G. A. Haywood, et al. Randomized trial comparing pulmonary vein isolation using the SmartTouch catheter with or without real-time contact force data. Heart Rhythm 13(9):1761-1767, 2016. https://doi.org/10.1016/j.hrthm.201 6.05.011.

${ }^{28}$ Weiss, C., M. Antz, O. Eick, K. Eshagzaiy, T. Meinertz, and S. Willems. Radiofrequency catheter ablation using cooled electrodes: impact of irrigation flow rate and catheter contact pressure on lesion dimensions. Pacing Clin Electrophysiol 25(4):463-469, 2002. https://doi.org/10.1046/ j.1460-9592.2002.00463.x.

${ }^{29}$ Wittkampf, F. H., and H. Nakagawa. RF catheter ablation: lessons on lesions. Pacing Clin Electrophysiol 29(11):1285-1297, 2006. https://doi.org/10.1111/j.1540-815 9.2006.00533.x.

${ }^{30}$ Yokoyama, K., H. Nakagawa, D. C. Shah, H. Lambert, G. Leo, N. Aeby, et al. Novel contact force sensor incorporated in irrigated radiofrequency ablation catheter predicts lesion size and incidence of steam pop and thrombus. Circ Arrhythm Electrophysiol 1(5):354-362, 2008. https://doi.or g/10.1161/CIRCEP.108.803650.

${ }^{31}$ Yonas, E., R. Pranata, B. B. Siswanto, and H. B. Abdulgani. Comparison between surgical and catheter based ablation in atrial fibrillation, should surgical based ablation be implemented as first line? A meta-analysis of studies. Indian Pacing Electrophysiol J 20(1):14-20, 2020. https://d oi.org/10.1016/j.ipej.2019.12.001.

Publisher's Note Springer Nature remains neutral with regard to jurisdictional claims in published maps and institutional affiliations. 